Canadian

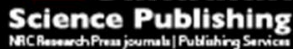

Canadian Geotechnical Journal Revue canadienne de géotechnique

\title{
A strength criterion for frozen sodium sulfate saline soil
}

\begin{tabular}{|r|l|}
\hline Journal: & Canadian Geotechnical Journal \\
\hline Manuscript ID & cgj-2015-0569.R1 \\
\hline Danuscript Type: & Article \\
\hline Complete List of Authors: & $\begin{array}{l}\text { Liao, Mengke; Cold and Arid Region Environmental and Engineering } \\
\text { Institute, Chinese Academy of Sciences, Chinese Academy of Sciences; } \\
\text { University of the Chinese Academy of Sciences } \\
\text { Lai, Yuanming; Cold and Arid Regions Environmental Research Institute, } \\
\text { Chinese Academy of Sciences, State Key Laboratory of Frozen Soil } \\
\text { Engineering; School of Civil Engineering, Lanzhou Jiaotong University } \\
\text { Wang, Chong; School of Civil Engineering and Mechanics, Lanzhou } \\
\text { University; State Key Laboratory of Frozen Soil Engineering, Cold and Arid } \\
\text { Regions Environmental and Engineering Institute, Chinese Academy of } \\
\text { Sciences }\end{array}$ \\
\hline Keyword: & $\begin{array}{l}\text { sodium sulphate, frozen saline soil, strength criterion, freezing } \\
\text { temperature, deviatoric plane }\end{array}$ \\
\hline \multicolumn{2}{|c}{} \\
\hline
\end{tabular}




\title{
A strength criterion for frozen sodium sulfate saline soil
}

\author{
Mengke Liao ${ }^{1,2}$, Yuanming Lai ${ }^{1,3 *}$, Chong Wang ${ }^{1,4}$ \\ (1. State Key Laboratory Frozen Soil Engineering, Cold and Arid Region Environmental and \\ Engineering Institute, Chinese Academy of Sciences, Lanzhou, Gansu 730000, China; 2. \\ University of Chinese Academy of Sciences, Beijing, 100049; 3. School of Civil Engineering, \\ Lanzhou Jiaotong University, Lanzhou, Gansu 730070; 4. School of Civil Engineering and \\ Mechanics, Lanzhou University, Lanzhou, Gansu 730000, China) \\ * Corresponding author. Tel.:+86 9314967288 \\ E-mail address: ymlai@lzb.ac.cn.
}

\begin{abstract}
Salt content is proven to be an important influencing factor on the mechanical property of frozen saline soils, whose strength criterion is different from that of unfrozen saline soils or frozen soils without salts. In this paper, a series of conventional triaxial tests are carried out for frozen saline soils with sodium sulphate at the temperature of $-6^{\circ} \mathrm{C}$. A strength criterion of the frozen saline soils, including the influence of salt content, is established by using the generalized nonlinear strength theory. Based on the conventional triaxial test results, a modified hydrostatic pressure expression is proposed according to the critical strength function of Modified Cam Clay model in meridian plane. The influence of salt content on the shear strength of the frozen saline soils is investigated according to their freezing temperature curves, and also the formation of salt and ice crystals. The relationship between salt content and friction angle is analyzed. The proposed strength criterion of frozen saline soil is proved to be reliable by extrusion elongation triaxial tests. The proposed strength criterion can reasonably reflect the major nonlinear strength characteristics of the frozen saline soils, including the influences of salt content changing, pressure melting and ice crushing.
\end{abstract}

Keywords: sodium sulphate, frozen saline soil, strength criterion, freezing temperature, deviatoric plane 


\section{Introduction}

Large variation has been found in the mechanical properties of frozen saline soils with different salt contents in cold regions, since the freezing temperature of saline soil is greatly affected by salt content. For frozen saline soils, the influence of sulfate on the mechanical and structural characteristics of frozen soils is very much intense. Moreover, sulfate saline soil is widely distributed in the western cold regions in China (Xu et al. 1995). With the development of engineering construction in these regions, the strength characteristic and related theory of frozen saline soils are urgently needed. The research on the mechanics characteristics of frozen saline soils, especially the influence of salt content, is rarely reported.

In general, the geomaterials can be taken as friction materials. Mohr-Coulomb criterion with linear strength envelopes in both meridian plane and deviatoric plane is widely used for geomaterials. However, a large number of studies have indicated that the linear Mohr-Coulomb is not suitable for most of geomaterials, and the nonlinear strength envelopes are often employed to reflect the effect of intermediate principal stress (Houlsby 1986; Liu and Carter 2003; Lai et al. 2010; Mortara 2015). For frozen soils, Lai et al. (2010) proposed a nonlinear Mohr strength criterion to describe the shear strength based on the experimental results. Hydrostatic pressure also greatly affects shear strength, and the strength envelopes were presented as an open or closed parabolas (Qi and Ma 2007; Mortara 2008), and exponential or power functions (Hoek and Brown, 1980; Yao et al. 2015). Some researchers have also studied the shape function in deviatoric plane under various complex stress states of geomaterials, and abundant results were obtained (Gudehus 1973; Argyris et al. 1974; Podgorski 1985; Matsuoka et al. 1999; Bigoni and Piccolroaz 2004; Mortara 2008). Zienkiewicz and Pande (1977) proposed a widely-used nonlinear unified strength criterion. With respect to sandy soils, two popular strength criteria, abbreviated as MN and LD, were proposed by Matsuoka and Nakai (1974) and Lade and Duncan (1975), respectively. They were later developed by many researchers, such as Gajo and Muir Wood (1999), and Pestana et al. (2002). Based on the MN criterion and the corresponding transforming stress method, Yao et al. (2009) proposed a UH model to research the overconsolidated clays. The proposed model could be applied conveniently to three-dimensional stress states to predict the stress-strain relationship of clays under cyclic loading. Impressive advances have been made in research on unified 
hardening law. Although a lot of improvements have been made for the MN and LD criteria, there are still some troubles when being applied for frozen soils. Yang et al. (2010 a; 2010 b) established a new strength criteria based on MN and LD criteria for frozen soils. In order to overcome the limitations of the new strength criteria, a better one, based on Hoek-Brown criterion, was proposed by Yang et al. (2013). In addition, Liu et al. (2011) introduced a material coefficient into a unified strength criterion, and realized the interconversion between the MN and LD criteria. On the research of yield criterion, Yao and Sun (2000) developed a revised model by applying Lade's criterion to Cam-Clay model. This model is capable of predicting the drained and undrained behavior of soils in general stress conditions. Other researchers adopted this method to develop some other critical strength criteria (e.g. Mortara 2008; Yao et al. 2004).

Compared with general frozen soil, the structure of frozen saline soil is changed with the precipitation of ice crystal and salt crystal in the freezing process, so the strength criterion of frozen saline soil is more complex than that of other frozen soils. Due to the complex structure of frozen saline soils, plenty of existed strength criteria (Houlsby 1986; Matsuoka and Nakai 1974; Lade and Duncan 1975; Liu and Carter 2003; Lai et al. 2010; Mortara 2015) cannot be directly used. The existence of salt lowers the freezing temperature, which consequently causes the decrease of the content of ice crystals with the increase of salt content. In addition, salt crystallization enhances the bond strength. It has been proved that the content of sodium sulfate has a large influence on the mechanical properties of frozen soils (Wan 2015). Therefore, in order to establish a new strength criterion, further research work should be conducted on the influence of salt content on the shear strength of frozen saline soils.

In this paper, Extruding Elongation Triaxial (EET) test apparatus is developed by modifying the conventional triaxial test apparatus, and a series of experiments for frozen saline soils are carried out. In order to overcome the limitation of general strength criterion, a unified strength criterion, considering the effect of salt content, is established in principal stress space based on the test results. The shape function of the proposed strength criterion in deviatoric plane is presented by introducing a weighting factor $\alpha$ into MN and LD criteria. 


\section{Analysis of the critical strength of frozen saline soils}

\subsection{Critical strength curves of frozen sodium sulphate saline soils}

The tested saline soil was collected from the permafrost regions on the Qinghai-Tibet plateau. In order to prepare soil samples with different salt contents, the natural saline soil was firstly desalinated with distilled water. The desalinated soil was dried at a constant temperature of $105^{\circ} \mathrm{C}$ for $24 \mathrm{~h}$ and then pulverized. Finally, cylindrical soil samples with the diameter of $61.8 \mathrm{~mm}$ and the height of $125 \mathrm{~mm}$ were made by the uniform mixture of soil, anhydrous $\mathrm{Na}_{2} \mathrm{SO}_{4}$ and water. Four types of salt contents, i.e. $0.0,0.5,1.5$, and $2.5 \%$, were obtained. The MTS- 810 material testing system (MTS Systems Corporation, USA) was modified by adding a cooling equipment for triaxial tests of frozen soils in this study. The apparatus was presented in a previous paper (Yang et al. 2010). The test procedure was: 1) keeping the temperature of soil samples at $-6{ }^{\circ} \mathrm{C}$ using the cooling equipment; 2) loading to a constant confining pressure; 3) keeping the consolidation state for 2 hours; and 3) increasing axial pressure at a certain strain rate until the soil sample failure.

The critical strength test results of the frozen soils with different salt contents are shown in Fig. 1. It can be found that the strength increases with the increase of confining pressure under relatively low pressures, whereas under relatively high pressures, the increasing amplitude slows down with the increase of the confining pressure for any salt content tests. The possible reason is that the microcracks show a tendency to disappear under relatively low pressures, but they are more likely to expand under relatively high pressures because of ice crystals melting and rupture (Fish 1991; Ma et al. 1999). Additionally, from Fig.1, it can be seen that the salt contents have a small effect on the critical strength under relatively low confining pressures, but an increasingly large effect with the increase of confining pressure. The precipitation of salt crystals in soil increases the bond strength between soil particles. Due to the bond effect of salt crystal, the shear strengths are higher when the soils with the higher salt contents, but the incremental strengths are not very high with the increase of salt contents under relatively low pressures. Unlike the pressure melting of ice crystals, the increase of confining pressure has little effect on salt crystals. Therefore, the higher the salt contents, the smaller the influence of pressure melting characteristics on the shear strength. And the higher the salt content is, the lower the curving degree of critical strength curve is, except that the shear strength of soil sample is minimum when the salt content is 
$0.5 \%$.

Fig. 1 Critical strength test results for the frozen saline soils with different salt contents

\subsection{The modification for generalized effective hydrostatic pressure}

In principal stress space, the stress invariants and stress Lode angle can be expressed by

$$
\begin{aligned}
& I_{2}=I_{1}^{2} / 3-J_{2} \\
& I_{3}=J_{3}+I_{1} I_{2} / 3-2 I_{1}^{3} / 27 \\
& \theta_{\sigma}=\frac{1}{3} \arcsin \left(-\frac{3 \sqrt{3}}{2} \cdot \frac{J_{3}}{\left(\sqrt{J_{2}}\right)^{3}}\right),-\frac{\pi}{6} \leq \theta_{\sigma} \leq \frac{\pi}{6} \\
& J_{3}=\frac{1}{3} s_{i j} s_{j k} s_{k i}
\end{aligned}
$$

where $I_{1}, I_{2}$ and $I_{3}$ are first, second and third principal stress invariants, respectively. $J_{3}$ is the third invariant of deviatoric stress, and $\theta_{\sigma}$ is stress Lode angle. In $p-q$ stress space, the generalized stresses can be expressed by

$p=\frac{1}{3} \sigma_{i i}=\frac{1}{3} I_{1}$

$$
q=\sqrt{3 J_{2}}=\sqrt{\frac{3}{2} s_{i j} s_{i j}}
$$

where $p, q$ and $\sigma_{i j}$ are hydrostatic pressure, deviatoric stress and total stress tensor, respectively.

The stress deviatoric tensor is denoted by $s_{i j}$ and $s_{i j}=\sigma_{i j}-p \delta_{i j}$, where $\delta_{i j}$ is Kronecker function.

$J_{2}$ is the second invariant of deviatoric stress.

Usually, there are certain tensile strengths for frozen saline soils due to the cementation effect of salt and ice crystals. This kind of cementation characteristic of frozen saline soil is very similar to the cohesive characteristic of cemented clay. Suebsuk et al (2010) proposed a constitutive model based on the Structure Cam Clay (SCC) model to simulate the mechanical behaviors of cemented clay. Horpibulsuk et al. (2004) pointed that the cohesive effect of cemented clay can strongly hinder the process of shear strain. With respect to frozen saline soil, the cementation effect is weakened due to the melting of ice under relative high pressure, which is so-called as "pressure melting" (Fish 1991; Ma et al. 1999). As a result, the critical strength curves are bended 
downwards with the increase of hydrostatic pressure, as shown in Fig. 1. From the test results, it can be seen that the stress ratios, namely the slopes of the curves, keep at a constant value $M_{0}$ during the initial loading stage, but decrease gradually with the increase of hydrostatic pressure.

In this study, the critical strength functions will be established from critical soil mechanics and Modified Cam model (MCC). A modified effective hydrostatic pressure $p^{*}$ is proposed to describe the phenomenon of pressure melting. Its expression is:

$p^{*}=p+p_{t}$

where $p_{t}$ is a function of hydrostatic pressure, describing the ice crystal pressure melting and breakage, critical strength reduction and effective stress degradation with the confining pressure increasing. According to the experimental results, $p_{t}$ can be assumed as the following expression (Lai et al. 2016):

$p_{t}=\frac{C_{l}}{M_{0}}\left(1-\frac{p}{B_{l}}\right) \exp \left(\frac{p}{B_{l}}\right)$

where $C_{l}$ is the intercept of the critical strength curve in $p-q$ plane. $M_{0}$ is the initial critical stress ratio. The parameter $B_{l}$ is related to pressure melting, which reflects the changing rate of $q$ with the increase of hydrostatic pressure.

\subsection{The parameter determination of the critical yield curves}

In principal stress space, the yield condition can be expressed by the three stress invariants, such as $F\left(I_{1}, I_{2}, I_{3}\right)=0$. Through the mutual conversion between stress invariants and stress components, the yield condition can be rewritten as

$F\left(p, q, \theta_{\sigma}\right)=0$

According to the general form of yield function proposed by Zheng (2010), Eq.(5) can also be expressed as

$F\left(p, q, \theta_{\sigma}\right)=F_{1}(p)+F_{2}\left(\frac{q}{g\left(\theta_{\sigma}\right)}\right)=0$

From Eq.(6), the deviatoric stress $q$ can be expressed as 
$q=f_{p-q}(p) \cdot g\left(\theta_{\sigma}\right)$

where $f_{p-q}(p)$ indicates the critical yield curve on meridian plane ( $p-q$ plane), and $g\left(\theta_{\sigma}\right)$ represents the shape function on deviatoric plane.

On deviatoric plane, we have the condition: $g\left(\theta_{\sigma}\right)=1$ when $\theta_{\sigma}=-\frac{\pi}{6}$ for conventional triaxial compression state. Based on the Modified Cam Clay model (MCC) (Roscoe and Burland 1968), the critical strength envelope function of frozen saline soils can be expressed by

$f_{p-q}(p)=M_{0} p^{*}=M_{0}\left(p+p_{t}\right)$

Substituting Eq.(4) into Eq.(8), the strength envelope formula of frozen saline soil can be given by

$f_{p-q}(p)=M_{0} p+C_{l}\left(1-\frac{p}{B_{l}}\right) \exp \left(\frac{p}{B_{l}}\right)$

If $C_{l}=0$, it means that there is no cohesion between the soil particles and ice/salt crystals, and thus the strength envelope line will be the same as that of MCC. For Structure Cam Clay model, Horpibulsuk et al. (2010) pointed that the incremental rate of shear strength of cemented clay keeps at a constant value with the increase of hydrostatic pressure. For frozen soil, the critical strength function can be degenerated to Structure Cam Clay model if the effect of pressure melting characteristic of the ice crystal is ignored. However, as a kind of special mixed granular material, the pressure melting phenomenon of frozen soil cannot be ignored under high confining pressure.

In the strength envelope equation, each material parameter has its physical meaning. The values of parameters reflect the shape change of the strength envelope. The sensitivity of the parameters can be seen from Fig. 2 .

Fig. 2 The effect of the parameter changing on critical strength envelope for the frozen saline soils with the salt content of $1.5 \%$

From Fig. 2(a), it can be seen that the initial critical stress ratio $M_{0}$ reflects the initial slope of the strength envelope. It is a function of salt content. During the initial loading stage, the applied load is so small that a negligible effect on the cohesive force is only generated. The initial critical stress ratio keeps at a constant value under relatively low confining pressure. Therefore, the initial 
critical stress ratio is the maximum during the whole loading process. The parameter $C_{l}$ is the intercept of critical strength curve, meaning the cohesive force of frozen saline soil. From Fig. 2(c), it can be seen that the bond strength between the soil particles and ice/salt crystal are weakening with the decrease of $B_{l}$, which reflects the pressure melting characteristic of frozen saline soil. On the other hand, the critical strength curve will be the same as that of Structure Cam Clay model when the parameter $B_{l}$ approaches to infinity.

The three parameters of the critical strength curves, shown in Fig. 1, can be obtained by curve fitting. The obtained parameters are given in Table 1.

Table 1 Parameters of critical strength with different salt contents

\section{The effect of salt content on shear strength and related parameters}

From the above analyses, it can be seen that the salt content has a great influence on the shear strength of frozen saline soil. Of note is that the shear strength doesn't always increase with the increase of salt content, especially, the minimum value appears for the frozen saline soil with the salt content of $0.5 \%$. Additionally, salt content also has an influence on the strength envelops and their parameters $M_{0}, B_{l}$ and $C_{l}$.

\subsection{The influence of salt content on the shear strength of frozen saline soil}

As shown in Fig. 1, a more obvious influence of salt content is presented under the relatively high hydrostatic pressure. The shear strength generally increases with salt content increasing. The minimum value doesn't appear at the soil sample without salt, but appears at the soil sample with the salt content $0.5 \%$. The shear strength increases with the increase of salt content when the salt content is higher than $0.5 \%$. As for the three parameters, it is found that the critical stress ratio $M_{0}$ increases with the increase of salt content. The parameters $B_{l}$ and $C_{l}$ firstly decrease and then increase with the increase of salt content, and reach the minimum value at the salt content of $0.5 \%$. These phenomena are analyzed and discussed from the two aspects as following:

(1) The cooling temperature curve. The cooling temperature curves were obtained by cooling the frozen saline soils with the salt contents $0.0 \%, 0.5 \%, 1.5 \%$, and $2.5 \%$ (the salt is anhydrous 
$\mathrm{Na}_{2} \mathrm{SO}_{4}$ fine particles), respectively, from the initial temperature of $10^{\circ} \mathrm{C}$. Referring to the previous researches (Wan et al. 2015; Xu 2010; Bing and Ma 2011), the freezing temperatures of the frozen saline soils can be determined. From the cooling temperature curves (Fig. 3), it can be seen that the freezing temperature are $-0.19{ }^{\circ} \mathrm{C},-1.47{ }^{\circ} \mathrm{C},-1.54{ }^{\circ} \mathrm{C}$ and $-1.58{ }^{\circ} \mathrm{C}$ for the frozen saline soils with salt contents of $0.0 \%, 0.5 \%, 1.5 \%$, and $2.5 \%$, respectively. In the cooling process, the liquid water of the soil sample starts to freeze when the temperature reaches its freezing temperature, and a part of unfrozen water still keeps the unfrozen state. The first inflection point of the temperature curves means that the soil sample is in the initial ice-water phase transition region. After the inflection point, the temperature starts to escalate due to a lot of heat releasing during water-ice phase change. Then, the temperatures reach the highest points, which are just the freezing temperatures of soil samples. Besides water-ice phase change, salt crystallization may be another influencing factor of the temperature curves. Another inflection point appears at the frozen saline soil with the salt content $0.5 \%$ after water-ice phase change, which may be caused by heat releasing during salt crystallization. This phenomenon doesn't happen for the other frozen saline soils, possibly indicating that salt crystallization is finished before the freezing temperatures.

(2) The process of salt crystallization. The existence of sodium sulfate lowers the freezing temperatures of saline soils by changing the unfrozen water activity (Wan et al. 2015). According to the test results, salt crystallization doesn't happen near the freezing temperature when the salt content is lower than $0.5 \%$. A tinny inflection point appears before the freezing temperature for the frozen saline soil with the salt content $1.5 \%$. That is the moment of salt crystallization happening. Wan (2015) pointed that salt crystallization may happen at positive temperatures when the salt content is higher than $2 \%$ for saline silt. Since the shear strength might be influenced by salt crystallization, two kinds of situations will be analyzed for the frozen saline soils with the salt content lower or higher than $0.5 \%$, as follows.

i) The formation of ice crystallization is prior to salt crystallization for the frozen saline soils with the salt contents from 0.0 to $0.5 \%$. A lot of heat releases during the process of salt crystallization. When the soil temperature is higher than the freezing temperature, the sodium sulfate solution in the soil is not saturated, resulting in no salt crystallization occurring. On the other hand, when the temperature is lower than the freezing temperature, some part of unfrozen water will be consumed by water-ice phase change, and consequently the sodium sulfate solution 
in the soil reaches the supersaturated state and the sodium sulfate begins to crystallize. From the temperature curve of the salt content $0.5 \%$, it can be seen that the starting temperature of salt crystallization is a little bit lower than the freezing temperature. This means both ice and salt crystallizations occur practically at the same time. Due to the changes of the unfrozen water activities, no salt crystallization occurs when ice begins to crystallize with the salt content lower than $0.5 \%$. Therefore, the shear strength of frozen saline soils decreases with the increase of salt contents when the salt content of sodium sulfate is from 0.0 to $0.5 \%$.

ii) The freezing temperatures and the amounts of ice crystallization are almost maintained unchanged for the frozen saline soils with the salt contents from 0.5 to $2.5 \%$. Due to water absorption of soil particles, the supersaturated state is reached above the freezing temperature. The precipitation of sodium sulfate crystals precedes the formation of ice crystals, and the ice crystals directly bond with sodium sulfate crystals and soil particles. As a result, the more the salt crystals are, the higher the bond strength between the crystals and the soil particles will be, so the higher salt content results in the higher shear strength of frozen saline soils.

The influence of salt content on shear strength is illustrated in Fig. 4. It can be seen that the minimum value appears at the salt content of $0.5 \%$, and a nonlinear relationship is found between the shear strength and salt content. As we can see, the influence of salt content on parameters $B_{l}$ and $C_{l}$ are consistent with that on shear strength. The parameters $B_{l}$ and $C_{l}$ also behave firstly decreasing and then increasing with the increase of salt content, as shown in Table 1.

Fig. 3 Cooling temperature curves for the saline soils with different contents of sodium sulfate

Fig. 4 Effect of the salt contents on the shear strengths

\subsection{The influence of salt content on the strength envelope}

Based on Mohr strength theorem, in $\sigma-\tau$ space, the yield criterion can be expressed as

$$
f\left(\sigma_{1}, \sigma_{3}\right)=\left(\sigma-\frac{\sigma_{1}+\sigma_{3}}{2}\right)^{2}+\tau^{2}-\left(\frac{\sigma_{1}-\sigma_{3}}{2}\right)^{2}=0
$$

For conventional triaxial tests, by substituting $p=\left(\sigma_{1}+2 \sigma_{3}\right) / 3$ and $q=\sigma_{1}-\sigma_{3}$ into Eq.(10), we can obtain the following formula

$$
f(p, q)=(\sigma-p-q / 6)^{2}+\tau^{2}-q^{2} / 4=0
$$


From Eq.(9), the strength envelope of conventional triaxial test $f_{p-q}(p)$ can be rewritten as

$g(p, q)=M_{0} p+C_{l}\left(1-\frac{p}{B_{l}}\right) \exp \left(\frac{p}{B_{l}}\right)-q=0$

Based on the envelope theory, the following relationship can be given

$$
\frac{\partial f}{\partial p} \cdot \frac{\partial g}{\partial q}-\frac{\partial f}{\partial q} \cdot \frac{\partial g}{\partial p}=0
$$

Substituting Eqs.(11) and (12) into Eq.(13), for the nonlinear strength criterion of frozen saline soil, the normal stress $\sigma$ related to $p$ and $q$ can be obtained by

$$
\sigma=\frac{\left[M_{0}-\frac{C_{l}}{B_{l}^{2}} p \exp \left(\frac{p}{B_{l}}\right)\right]\left[\frac{1}{6}\left(p+\frac{1}{6} q\right)-\frac{1}{2} q\right]+2\left(p+\frac{1}{6} q\right)}{2+\frac{1}{6}\left[M_{0}-\frac{C_{l}}{B_{l}^{2}} p \exp \left(\frac{p}{B_{l}}\right)\right]}
$$

Substituting Eq.(14) into Eq.(11), the shear stress $\tau$ can also be calculated by

$$
\tau=\sqrt{\frac{q^{2}}{4}-\left\{\frac{\left[M_{0}-\frac{C_{l}}{B_{l}^{2}} p \exp \left(\frac{p}{B_{l}}\right)\right]\left[\frac{1}{6}\left(p+\frac{1}{6} q\right)-\frac{1}{2} q\right]+2\left(p+\frac{1}{6} q\right)}{2+\frac{1}{6}\left[M_{0}-\frac{C_{l}}{B_{l}^{2}} p \exp \left(\frac{p}{B_{l}}\right)\right]}-p-\frac{1}{6} q\right\}}
$$

In Eqs.(14) and (15), the generalized stresses $p$ and $q$ satisfy the equation $g(p, q)=0$. In $\sigma-\tau$ space, the friction angle of frozen saline soil can be calculated by

$$
\begin{aligned}
& \tan \phi=\frac{d \tau}{d \sigma}=-\frac{\partial f}{\partial \sigma} / \frac{\partial f}{\partial \tau}=-\frac{\sigma-p-\frac{1}{6} q}{\tau} \\
& \phi=\arctan \left(-\frac{\sigma-p-\frac{1}{6} q}{\tau}\right)
\end{aligned}
$$

Substituting parameters $M_{0}, B_{l}$ and $C_{l}$ into Eq.(15), the strength envelope can be depicted in $\sigma-\tau$ space. And then the relationship between hydrostatic pressure and friction angle of frozen saline soil with different salt contents can be obtained by Eq.(17), as shown in Fig. 5.

Fig. 5 Relationship between hydrostatic pressure and friction angle for the frozen saline soils with different 
salt contents.

It is supposed that the value of friction angle is initial friction angle when the hydrostatic pressure $\mathrm{p}=0$. From Fig.5, it can be seen that the friction angles decrease with the increase of hydrostatic pressure due to pressure melting. The influence of salt content on friction angle is obvious. The higher the salt content is, the bigger the initial friction angle is. Under relatively low hydrostatic pressures (for example lower than $3 \mathrm{MPa}$ ), little changes of friction angles are found when hydrostatic pressure increasing for different salt contents. And a similar variation trend is found for shear strength. Under the same hydrostatic pressure, the minimum value of the friction angle is not corresponding to salt content $0.0 \%$, but to salt content $0.5 \%$, when the hydrostatic pressure exceeds a certain value (for example 10MPa).

\section{Strength criterion for frozen saline soil}

At present, the true triaxial tests on frozen saline soils under general stress states cannot be carried out due to the limitation of test apparatus. Moreover, it is difficult to apply the strength criterion of unfrozen soils directly to the research of frozen soil. The research results of Liu et al. (2011) and Yao et al. (2015) indicated that the strength curves of MN criterion and LD criterion were approximate in deviatoric plane for sand materials. Moreover, as we know, there are many differences in the failure surfaces between frozen soils and unfrozen soils in principal stress space Firstly, since the bond strength is very large among the ice/salt crystals and soil particles, failure surfaces of frozen soils do not pass through the origin of coordinates, but the strength curves in $p-q$ plane pass through the point of isotropic tension due to the existence of tensile strength of frozen soil. Secondly, the strength curves in $p-q$ plane are not straight lines. The strengths firstly increase to peak values with the increase of confining pressure, and afterwards decrease due to pressure melting or crushing phenomena under high confining pressures. Therefore, the previous strength criteria, such as Matsuoka-Nakai and Lade criteria, are unsuitable for frozen saline soils.

\subsection{Shape function analysis in deviatoric plane}

In the study of strength criterion, Matsuoka and Nakai (1974) and Lade and Duncan (1975) proposed strength criteria for geomaterials, i.e., MN and LD strength criteria, respectively. They 
are expressed as:

$$
\frac{I_{1} I_{2}}{I_{3}}=k_{M N} ; \frac{I_{1}^{3}}{I_{3}}=k_{L D}
$$

where $k_{M N}$ and $k_{L D}$ are two material parameters related to friction angle $\phi$, which are expressed as:

$k_{M N}=\frac{9-\sin ^{2} \phi}{1-\sin ^{2} \phi} ; \quad k_{L D}=\frac{(3-\sin \phi)^{3}}{(1+\sin \phi)(1-\sin \phi)^{2}}$

At present, there are many unsolved problems to carry out true triaxial tests for frozen soils. From the structure point of view, frozen saline soil has cohesion strength due to the existences of ice and salt crystals, but the cohesion can be easily influenced by pressure melting or crystals crushing. Therefore, based on the empirical strength criteria and the research results of Liu and Carter (2003), a strength criterion of frozen saline soil are proposed as

$$
\begin{aligned}
& \frac{\alpha I_{1}^{3}+(1-\alpha) I_{1} I_{2}}{I_{3}}=k_{i} \\
& k_{i}=\frac{\alpha(3-\sin \phi)^{3}}{(1+\sin \phi)(1-\sin \phi)^{2}}+\frac{(1-\alpha)\left(9-\sin ^{2} \phi\right)}{1-\sin ^{2} \phi}
\end{aligned}
$$

where $\alpha$ and $k_{i}$ are material parameters.

Substituting Eqs.(1) and (21) into Eq.(20), the following expression can be obtained

$$
\left(k_{i}-18 \alpha-9\right)\left(\frac{I_{1}}{\sqrt{J_{2}}}\right)^{3}-27\left(\frac{k_{i}}{3}+\alpha-1\right)\left(\frac{I_{1}}{\sqrt{J_{2}}}\right)-6 \sqrt{3} \sin 3 \theta_{\sigma}=0
$$

Based on the solution to univariate cubic equation, the solution of Eq. (22) can be obtained as:

$$
\frac{I_{1}}{\sqrt{J_{2}}}=\sqrt{\frac{12\left(k_{i}+3 \alpha-3\right)}{k_{i}-18 \alpha-9}} \sin \left[\frac{\pi}{3}+\frac{1}{3} \arcsin \left(A \sin 3 \theta_{\sigma}\right)\right]
$$

where $A=\sqrt{\frac{k_{i}^{2}\left(k_{i}-18 \alpha-9\right)}{\left(k_{i}+3 \alpha-3\right)^{3}}}$

In $p-q-\theta_{\sigma}$ space, Eq.(23) can be rewritten as

$$
\frac{p}{q}=\frac{1}{3 \sqrt{3}} \frac{I_{1}}{\sqrt{J_{2}}}=\sqrt{\frac{4\left(k_{i}+3 \alpha-3\right)}{9\left(k_{i}-18 \alpha-9\right)}} \sin \left[\frac{\pi}{3}+\frac{1}{3} \arcsin \left(A \sin 3 \theta_{\sigma}\right)\right]
$$

From Eq.(24), the following expression can be obtained 
$q=p \sqrt{\frac{9\left(k_{i}-18 \alpha-9\right)}{4\left(k_{i}+3 \alpha-3\right)}} \frac{1}{\sin \left[\frac{\pi}{3}+\frac{1}{3} \arcsin \left(A \sin 3 \theta_{\sigma}\right)\right]}$

We have $\theta_{\sigma}=-\frac{\pi}{6}$ for the triaxial compression stress state. Regardless of the value of $\alpha$, by normalization, the value of the shape function $g\left(\theta_{\sigma}\right)$ is always equal to 1 when $\theta_{\sigma}=-\frac{\pi}{6}$, and then the shape function in deviatoric plane can be given by

$g\left(\theta_{\sigma}\right)=\frac{\sin \left[\frac{\pi}{3}-\frac{1}{3} \arcsin (A)\right]}{\sin \left[\frac{\pi}{3}+\frac{1}{3} \arcsin \left(A \sin 3 \theta_{\sigma}\right)\right]},-\frac{\pi}{6} \leq \theta_{\sigma} \leq \frac{\pi}{6}$

The radius ratio of triaxial tensile and triaxial compression in deviatoric plane, $\beta$, can be calculated by the following formula:

$\beta=\frac{g\left(\frac{\pi}{6}\right)}{g\left(-\frac{\pi}{6}\right)}=\frac{\sin \left(\frac{\pi}{3}-\frac{1}{3} \arcsin A\right)}{\sin \left(\frac{\pi}{3}+\frac{1}{3} \arcsin A\right)}$

The frozen saline soil, with the salt content of $1.5 \%$ and the initial friction angle $\phi_{0}=26.92^{\circ}$, is taken as an example to investigate the relationship between the parameters $\alpha$ and $\beta$. From Eqs. (21), (26) and (27), the relationship of $\alpha$ and $\beta$, shown in Fig.6, can be obtained. The shape function curves with different values of $\alpha$ in deviatoric plane are shown in Fig. 7. From Fig.7, it can be seen that the minimum radius ratio is equal to 0.5 , and the deviatoric plane curve is an equilateral triangle. When the maximum value of $\beta$ is equal to 1 , the deviatoric plane curve is a circle. If $|\alpha| \rightarrow \infty$, the limit value of $\beta$ is 0.818 . It is obvious that the failure criterion is MN when $\alpha=0$ and $\beta=0.738$, while the failure criterion is $\operatorname{LD}$ when $\alpha=1$ and $\beta=0.801$.

Fig. 6 Relationship between parameters $\alpha$ and $\beta$ for the frozen saline soil with the salt content of $1.5 \%\left(\phi_{0}\right.$

$$
\left.=26.92^{\circ}\right)
$$

Fig.7 Shape function curves with different values of $\alpha$ in deviatoric plane $\left(\phi_{0}=\mathbf{2 6 . 9 2}\right)$

The values of $\beta$ can be obtained by the method of curve fitting, and then the parameter $\alpha$ and the shape function $g\left(\theta_{\sigma}\right)$ in deviatoric plane can be calculated. Based on the convention triaxial 
compression and tensile tests, the radius ratio $\beta$ in deviatoric plane can be determined, and the shape functions in deviator plane can be established directly by using the parameter $\beta$. Supposing $\alpha=-0.2$ for frozen saline soil, the shape function curves in deviatoric plane for different friction angles are shown in Fig. 8. With the change of salt contents, the shape function curves in deviatoric plane are shown in Fig. 9 and the yield surfaces in principal stress space are presented in Fig. 10. From Fig. 9, it can be seen that the yield curves have some differences versus the different salt contents. The larger the hydrostatic pressure is, the bigger the influence of salt on the failure criterion will be. The shape function curves are very close for different salt contents under relatively low hydrostatic pressure.

Fig. 8 Shape function curves with different friction angles $\varphi$ and a constant value of $\alpha$

Fig. 9 Shape function curves of the frozen saline soils with different salt contents in deviatoric plane

Fig. 10 Yield surfaces of the frozen saline soils with different salt contents in principal stress space

\subsection{Parameter determination of strength criterion and discussion}

Substituting Eqs. (26) and (9) into Eq. (7), the yield function of the frozen saline soils can be given by

$$
q=\left[M_{0} p+C_{l}\left(1-\frac{p}{B_{l}}\right) \exp \left(\frac{p}{B_{l}}\right)\right] \frac{\sin \left[\frac{\pi}{3}-\frac{1}{3} \arcsin (A)\right]}{\sin \left[\frac{\pi}{3}+\frac{1}{3} \arcsin \left(A \sin 3 \theta_{\sigma}\right)\right]}
$$

where $A=\sqrt{\frac{k_{i}^{2}\left(k_{i}-18 \alpha-9\right)}{\left(k_{i}+3 \alpha-3\right)^{3}}}$ and $k_{i}=\frac{\alpha(3-\sin \phi)^{3}}{(1+\sin \phi)(1-\sin \phi)^{2}}+\frac{(1-\alpha)\left(9-\sin ^{2} \phi\right)}{1-\sin ^{2} \phi}$

Then, the yield surface equation of the frozen saline soils in principal stress space is expressed by Eq. (28). The related parameters of the yield surface equation can be determined by the test results.

In Section 2.3, the three parameters $M_{0}, B_{l}$ and $C_{l}$, related to critical strength curves, have been determined by the conventional triaxial tests, which are closely related to the salt contents. In Section 3.2, the changes of friction angle $\phi$ have been investigated based on the method of nonlinear Mohr strength criterion. In order to determine the strength criterion, the parameters $\alpha$ or 
$\beta$ should also be determined. If one of the parameters is determined, the other one can then be obtained from the relation of $\alpha$ and $\beta$ in Section 4.1.

In this paper, the strength criterion parameter $\beta$ can be obtained by the Extrusion Elongation Triaxial test (EET). The relationship of the three principal stresses in the EET tests is $\sigma_{1}=\sigma_{2} \geq \sigma_{3}$, when compressive stress is taken as positive. The EET test apparatus can be developed by modifying the pressure chamber of conventional triaxial test apparatus, and the axial loading and confining pressure can be controlled independently. In EET test, the deformation of the soil sample gradually increases in axial direction due to the extrusion by confining pressure, until the specimen is finally destroyed. The test method is that the axial and confining pressures are applied and kept for 2 hour consolidation firstly. Then, the axial loading is still kept constant, while the loading rate of confining pressure is $0.1 \mathrm{MPa} / \mathrm{min}$. Referring to the critical yield determination method of Brazilian Splitting tests for frozen and rock, the yield state of frozen saline soil is considered to reach when the axial strain is $2.5 \%$. The EET test results are shown in Fig. 11. From the test results, the yield stresses $p_{t e n}$ and $q_{t e n}$ can be determined. Since the shape function curves in deviatoric plane are the contour lines of hydrostatic $p$, the compressive yield stress components $p_{\text {com }}$ and $q_{\text {com }}$, corresponding to $p_{\text {ten }}$ and $q_{\text {ten }}$, respectively, can be determined from the critical strength curve of conventional triaxial tests. Finally, the parameter $\beta$ can be calculated from Eq. (27).

Fig. 11 Relationship between confining pressures and axial strain for the frozen saline soils with different salt contents

In order to verify the rationality of the established strength criterion for frozen saline soils, the tests of several stress states are performed on the soil samples with different salt contents, and the test results are summarized in Table 2. In the EET test apparatus, rubber membrane is used to isolate the oil and the specimen. Thus, the oil pressure is only applied to the radial direction of the sample, while the axial direction is only loaded by the axial external load. The apparatus has some limitations for applying very high hydrostatic pressure. Thus, the maximum confining pressure is no more than $8 \mathrm{MPa}$ in this study. Since the tensile test points cannot be completely determined 
under the high hydrostatic pressure, the shape function curves in deviatoric plane under high hydrostatic pressure can indirectly be predicted by the parameters obtained under relatively low hydrostatic pressures. According to EET test results, the parameters $\alpha$ and $\beta$ versus different salt contents are listed in Table 2.

\section{Table 2 Related parameters obtained from the EET tests}

From Table 2 and Fig. 7, it can be concluded that the shape function curves, under low hydrostatic pressure, look like an equilateral triangle in deviatoric plane. With the increase of salt contents, the value of $\alpha$ decreases gradually, but its values are always changed around -0.2 for the samples with different salt contents. From Section 3.1 and the EET tests, the minimum values of the critical strength and $\beta$ appear when the frozen saline soil with the salt content of $0.5 \%$. With the increase of hydrostatic pressure, the value of $\beta$ gradually increases, while the shape function curve in deviatoric plane gradually changes from an approximate equilateral triangle to an approximate circle, as shown in Fig. 9. This kind of characteristics is similar to that of Tien-Liao mudstone (Lee et al. 2002).

\section{Conclusions}

The complexities in both the structure and the component of frozen saline soils make its mechanical properties very complicated. In order to establish the strength criterion, a series of conventional triaxial compression tests and EET tests are carried out to frozen saline soils with $\mathrm{Na}_{2} \mathrm{SO}_{4}$ contents of $0.0 \%, 0.5 \%, 1.5 \%$, and $2.5 \%$, respectively. Some conclusions are made as follows:

(1) For the frozen saline soils with different salt contents, the critical strength curves under low confining pressure look like straight lines, and then bend downward with the increase of hydrostatic pressure under high confining pressure. The minimum critical strength appears when the salt content of $0.5 \%$.

(2) The phenomenon of pressure melting under high hydrostatic pressure can be described by the modified generalized effective stress. A critical strength function in meridian plane is presented. 
(3) The nonlinear Mohr-Coulomb equation of frozen saline soils with different salt contents, and the relationship between friction angle and hydrostatic pressure are established.

(4) The strength criterion and the yield surface equation of frozen saline soils are proposed. The reasonableness of the strength criterion is verified by the EET tests. The variation characteristic of the shape function curve in deviatoric plane is investigated.

\section{Acknowledgements}

We would like to thank very much the two anonymous reviewers whose constructive comments are helpful for this paper revision. This research was supported by National Natural Science Foundation of China (41230630), National key Basic Research Program of China (973 Program No. 2012CB026102), the Western Project Program of the Chinese Academy of Sciences (KZCX2-XB3-19) and the foundation of State Key Laboratory of Frozen Soil Engineering (SKLFSE-ZY-03).

\section{References}

Argyris, J.H., Faust, G., Szimmat, J., Warnke, E.P., and Willam, K.J. 1974. Recent developments in the finite element analysis of prestressed concrete reactor vessels. Nuclear Engineering and Design, 28(1): 42-75. doi:10.1016/0029-5493(74)90088-0.

Bigoni, D., and Piccolroaz, A. 2004. Yield criteria for quasibrittle and frictional materials. International Journal of Solids Structures, $\quad 41(11-12)$ : 2855-2878.doi: 10.1016/j.ijsolstr.2003.12.024.

Bing, H., and Ma, W. 2011. Laboratory investigation of freezing point of saline soil. Cold Regions Science and Technology, 67(1-2): 79-88.doi: 10.1016/j.coldregions.2011.02.008.

Chu, J. 1995. An experimental examination of the critical state and other similar concepts for granular soils. Canadian Geotechnical Journal, 32(6):1065-1075.doi: 10.1139/t95-104.

Fish, A.M. 1991.Strength of frozen soil under a combined stress state. In: Sixth International Symposium on Ground Freezing 1, 135-145.

Gajo, A., and Muir Wood, D. 1999. A kinematic hardening constitutive model for sands: the multiaxial formulation. International Journal Numerical and Analytical Methods in 
Geomechanics,

23(9):

$925-965$.

doi: 10.1002/(SICI)1096-9853(19990810)23:9<925::AID-NAG19>3.0.CO;2-M.

Gudehus, G. 1973. Elastoplastische stoffgleichungen fur trockenen sand. Ingenieur-Archiv, 42(3): 151-169.doi: 10.1007/BF00533041.

Hoek, E., and Brown, E.T. 1980. Empirical strength criterion for rock masses. Journal of the Geotechnical Engineering Division, 106(9):1013-1035.

Horpibulsuk, S., Miura, N., and Bergado, D. 2004. Undrained Shear Behavior of Cement Admixed Clay at High Water Content. Journal of Geotechnical and Geoenvironmental Engineering, 130(10): 1096-1105.doi: 10.1061/(ASCE)1090-0241(2004)130:10(1096).

Horpibulsuk, S., Liu, M.D., Liyanapathirana, D.S., and Suebsuk, J. 2010. Behaviour of cemented clay simulated via the theoretical framework of the structured cam clay model. Computer and Geotechnical, 37(1-2): 1-9.doi: 10.1016/j.compgeo.2009.06.007.

Houlsby, G.T. 1986. A general failure criterion for frictional and cohesive materials. Soils and Foundation, 26(2):97-101.

Lade, P.V., and Duncan, J.M. 1975. Elastoplastic stress-strain theory for cohesionless soil. Journal of the Geotechnical Engineering Division, 101(10):1037-1053.

Lai Y.M, Gao Z.H., Zhang, S.J., and Chang, X.X. 2010. Stress-strain relationships and nonlinear mohr strength criterion of frozen sand clay. Soils and Foundations, 50(1): 45-53. doi: $10.3208 /$ sandf.50.45.

Lai, Y.M, Liao, M.K., and Hu, K. 2016. A constitutive model of frozen saline sandy soil based on energy dissipation theory, International Journal of Plasticity, 78(3):84-113. doi:10.1016/j.ijplas.2015.10.008.

Lee, D.H., Juang, C.H., Lin, H.M., and Yeh, S.H. 2002. Mechanical behavior of Tien-Liao mudstone in hollow cylinder tests. Canadian Geotechnical Journal , 39(3):744-756. doi: 10.1139/T02-014.

Liu, M.D., and Carter, J.P. 2003. General strength criterion for geomaterials. International Journal of Geomechanics, 3(2): 253-259. doi: 10.1061/(ASCE)1532-3641(2003)3:2(253).

Liu, M.D., and Indraratna, B.N. 2011. General Strength Criterion for Geomaterials Including Anisotropic Effect. International Journal of Geomechanics, 3(11): 251-262. doi: 10.1061/(ASCE)GM.1943-5622.0000082. 
Ma, W., Wu, Z.W., Zhang, L.X., Chang, X.X. 1999. Analyses of process on the strength decrease in frozen soils under high confining pressures. Cold Regions Science and Technology, 29(1): 1-7. doi: 10.1016/S0165-232X(98)00020-2.

Matsuoka, H., and Nakai, T. 1974. Stress-deformation and strength characteristics of soil under three different principal stresses. Proceedings of the Japanese Society of Civil Engineers, 232: 59-70. doi: 10.2208/jscej1969.1974.232-59.

Matsuoka, H., Yao, Y.P., and Sun, D.A. 1999. The Cam-clay models revised by the SMP criterion. Soils and Foundation, 39(1): 81-95. doi: 10.3208/sandf.39.81.

Mortara, G. 2008. A new yield and failure criterion for geomaterials. Geotechnique, 58(2): 125-132. doi: 10.1680/geot.2008.58.2.125.

Mortara, G. 2015. A constitutive framework for the elastoplastic modelling of geomaterials. International Journal of Solids and Structures, 63: 139-152. doi: 10.1016/j.ijsolstr.2015.02.047.

Pestana, J. M., Whittle, A. J. and Salvati, L. A. 2002. Evaluation of a constitutive model for clays and sands. Part I: Sand behavior. International Journal Numerical and Analytical Methods in Geomechanics, 26(11): 1097-1121. doi: 10.1002/nag.237.

Podgorski, J. 1985. General failure criterion for isotropic media. Journal of Engineering Mechanics-ASCE, 111(2): 188-201.

Qi, J.L., and Ma, W. 2007. A new criterion for strength of frozen sand under quick triaxial compression considering effect of confining pressure. Acta Geotechnica, 2(3): 221-226. doi:10.1007/s11440-007-0034-z.

Roscoe, K. H., and Burland, J. B. 1968. On the generalized stress-strain behaviour of wet clay. Engineering plasticity. Cambridge: Cambridge University Press.

Sheng, D., Sloan, S. W., and Yu, H. S. 2000. Aspects of finite element implementation of critical state models. Computational Mechanics, 26(2): 185-196. doi: 10.1007/s004660000166.

Suebsuk, J., Horpibulsuk, S., and Liu, M.D. 2010. Modified structured cam clay: a generalised critical state model for destructured, naturally structured and artificially structured clays. Computer and Geotechnics, 37(7-8): 956-968. doi: 10.1016/j.compgeo.2010.08.002.

Wan, X.S., Lai Y.M., and Chong, W. 2015. Experimental Study on the Freezing Temperatures of Saline Silty Soils. Permafrost and Periglacial Processes, 26(2): 175-187. doi: 20 
10.1002/ppp.1837.

Wan, X.S. 2015. Laboratory Investigation on Salt Crystals Precipitation of Sulfate Saline Soil and Salt Transfer and Salt-Heaving Mitigation of Embankment in Cold Regions. PhD thesis, University of Chinese Academy of Sciences.

Xu, X.Z., Wang, J.C., Zhang, L.X., and Tao, Z.X. 1995. Mechanisms of frost heave and soil expansion of soils. Science Press: Beijing.

Xu, X.Z., Wang, J.C., and Zhang, L.X. 2010. Frozen soil physics. Science Press: Beijing.

Yang, Y.G., Lai, Y.M., and Li, J.B. 2010a. Laboratory investigation on the strength characteristic of frozen sand considering effect of confining pressure. Cold Regions Science and Technology, 60(3): 245-250. doi: 10.1016/j.coldregions.2009.11.003.

Yang, Y.G., Lai, Y.M., Dong, Y.H., and Li, S.Y. 2010b. The strength criterion and elastoplastic constitutive model of frozen soil under high confining pressures. Cold Regions Science and Technology, 60(2): 154-160. doi: 10.1016/j.coldregions.2009.09.001.

Yang, Y.G., Gao, F., and Lai, Y.M. 2013. Modified Hoek-Brown criterion for nonlinear strength of frozen soil. Cold Regions Science and Technology, 86: 98-103. doi: 10.1016/j.coldregions.2012.10.010.

Yao, Y.P., Hou, W., and Zhou, A.N. 2009. UH model: three-dimensional unified hardening model for overconsolidated clays Ge'otechnique 59(5): 451-469. doi: 10.1680/geot.2007.00029.

Yao, Y.P., Hu, J., Zhou, A.N., Luo, T., and Wang, N.D. 2015. Unified strength criterion for soils, gravels, rocks, and concretes. Acta Geotechnica, 10:749-759. doi: 10.1007/s11440-015-0404-x.

Yao, Y.P., and Sun, D.A. 2000. Application of Lade's criterion to Cam-clay model. ASCE, Journal of Engineering $\quad$ Mechanics, $\quad 126(1)$ : 112119. doi: 10.1061/(ASCE)0733-9399(2000)126:1(112).

Yao, Y.P., Sun D.A., and Luo, T. 2004. A critical state model for sands dependent on stress and density. International Journal for Numerical and Analytical Methods in Geomechanics. 28:323 - 337.doi: 10.1002/nag.340.

Zheng, Y.R., Shen, Z.J., and Gong, X.N. 2010. Generalized Plastic Mechanics, China Architecture and Building Press. pp 82-92.

Zienkiewicz, O.C., and Pande, G.N. 1977. Some useful forms of isotropic yield surfaces for soil 21 
and rock mechanics. In: Gudehus G (ed) Finite element in geomechanics. Wiley, New York, pp 179-190. 


\section{List of Figures}

Fig. 1 Critical strength test results for the frozen saline soils with different salt contents

Fig. 2 The effect of the parameter changing on critical strength envelope for the frozen saline soils with the salt content of $1.5 \%$

Fig. 3 Cooling temperature curves for the saline soils with different contents of sodium sulfate

Fig. 4 Effect of the salt contents on the shear strengths

Fig. 5 Relationship between hydrostatic pressure and friction angle for the frozen saline soils with different salt contents.

Fig. 6 Relationship between parameters $\alpha$ and $\beta$ for the frozen saline soil with the salt content of $1.5 \%\left(\phi_{0}=26.92^{\circ}\right)$

Fig.7 Shape function curves with different values of $\alpha$ in deviatoric plane $\left(\phi_{0}=26.92^{\circ}\right)$

Fig. 8 Shape function curves with different friction angles $\varphi$ and a constant value of $\alpha$

Fig. 9 Shape function curves of the frozen saline soils with different salt contents in deviatoric plane

Fig. 10 Yield surfaces of the frozen saline soils with different salt contents in principle stress space

Fig. 11 Relationship between confining pressures and axial strain for the frozen saline soils with different salt contents 


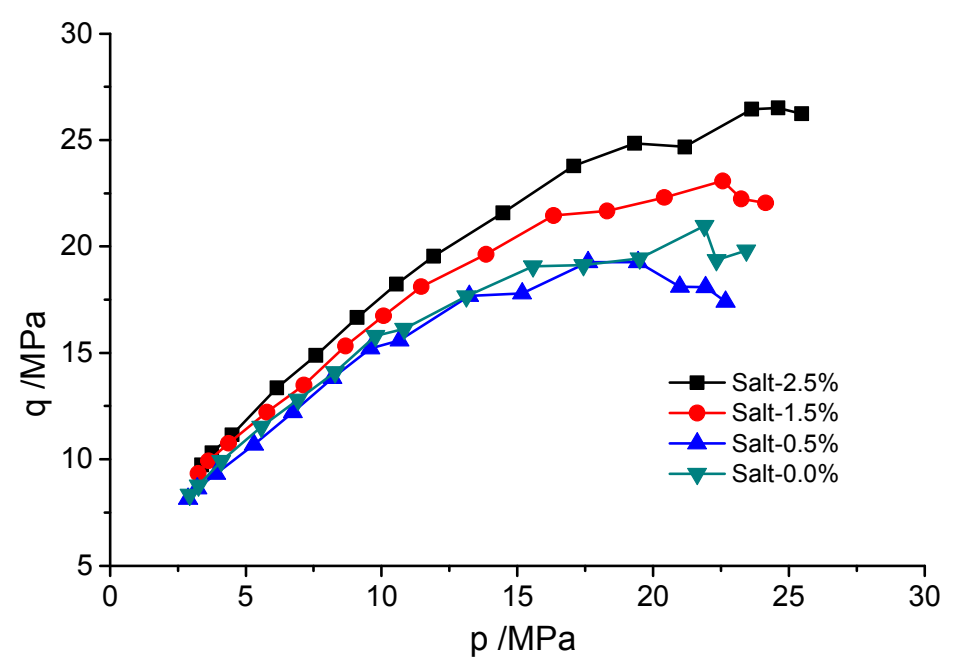

Fig. 1 Critical strength test results for the frozen saline soils with different salt contents 

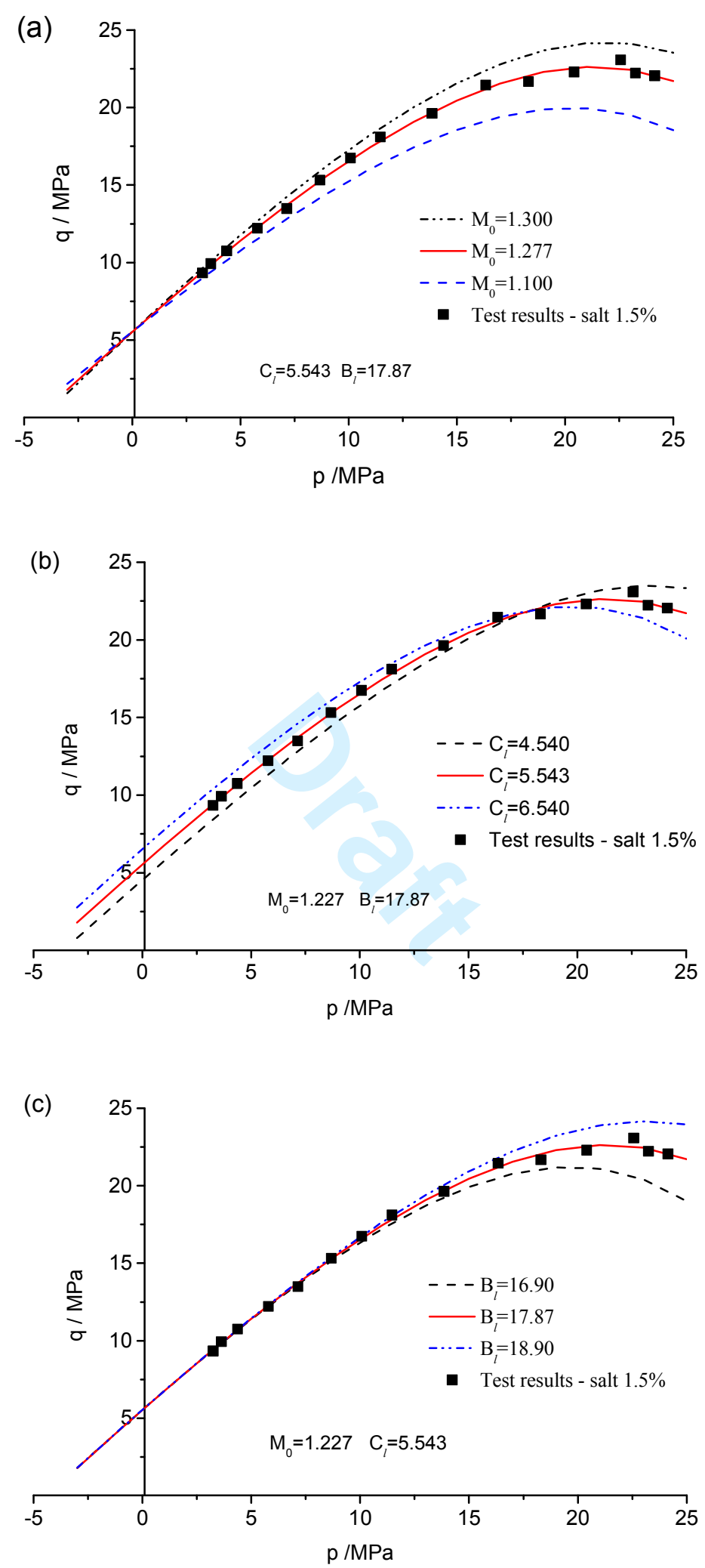

Fig. 2 The effect of the parameter changing on critical strength envelope for the frozen saline soils with the salt content of $1.5 \%$ 


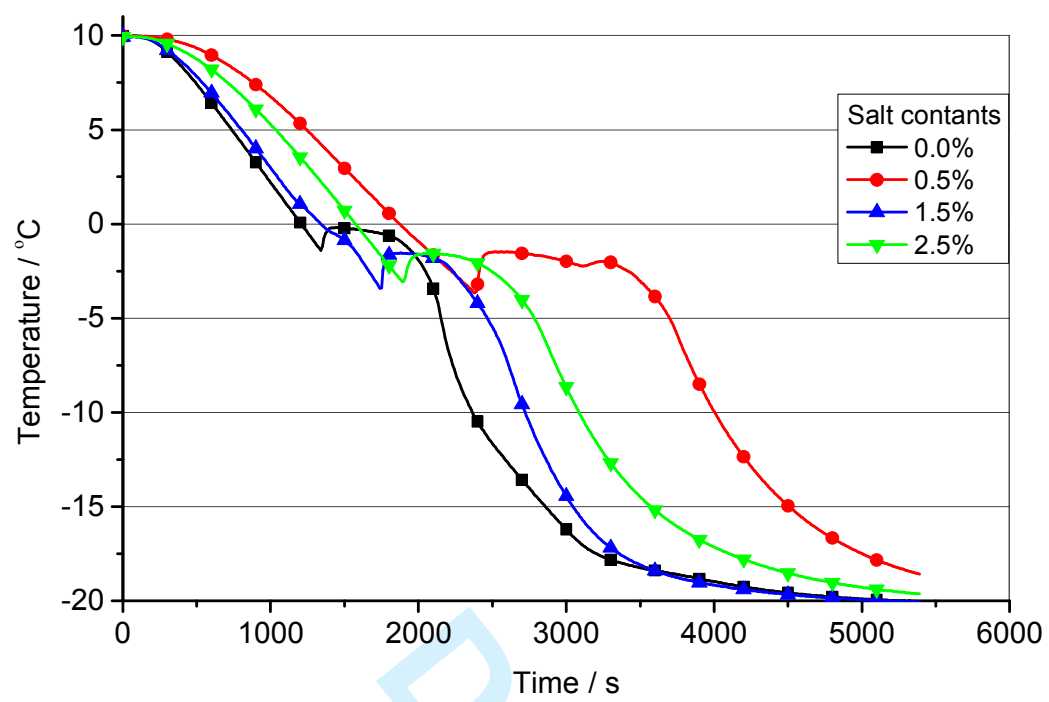

Fig. 3 Cooling temperature curves for the saline soils with different contents of sodium sulfate 


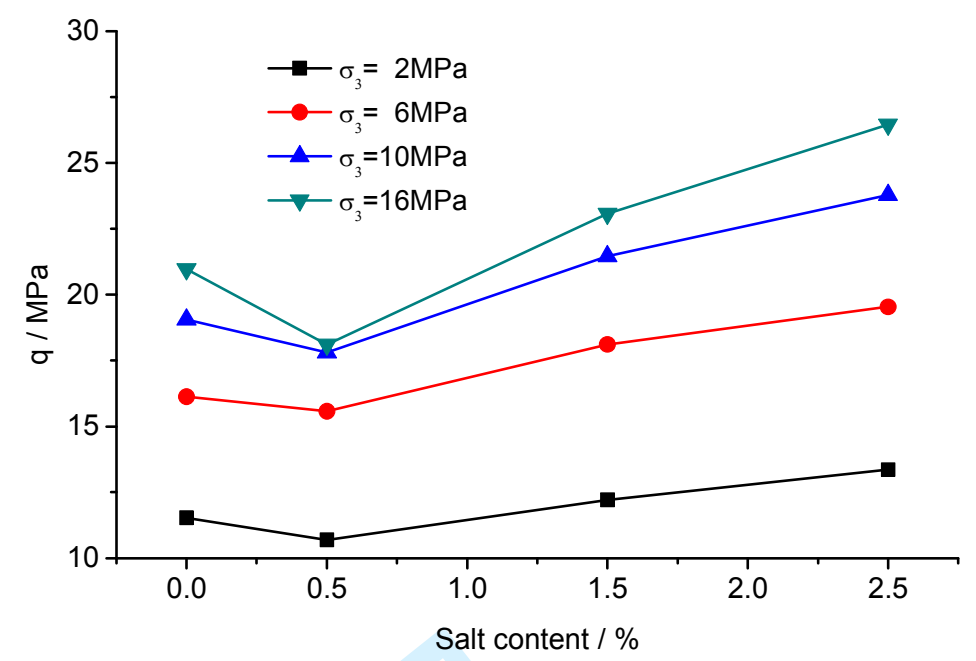

Fig. 4 Effect of the salt contents on the shear strengths 


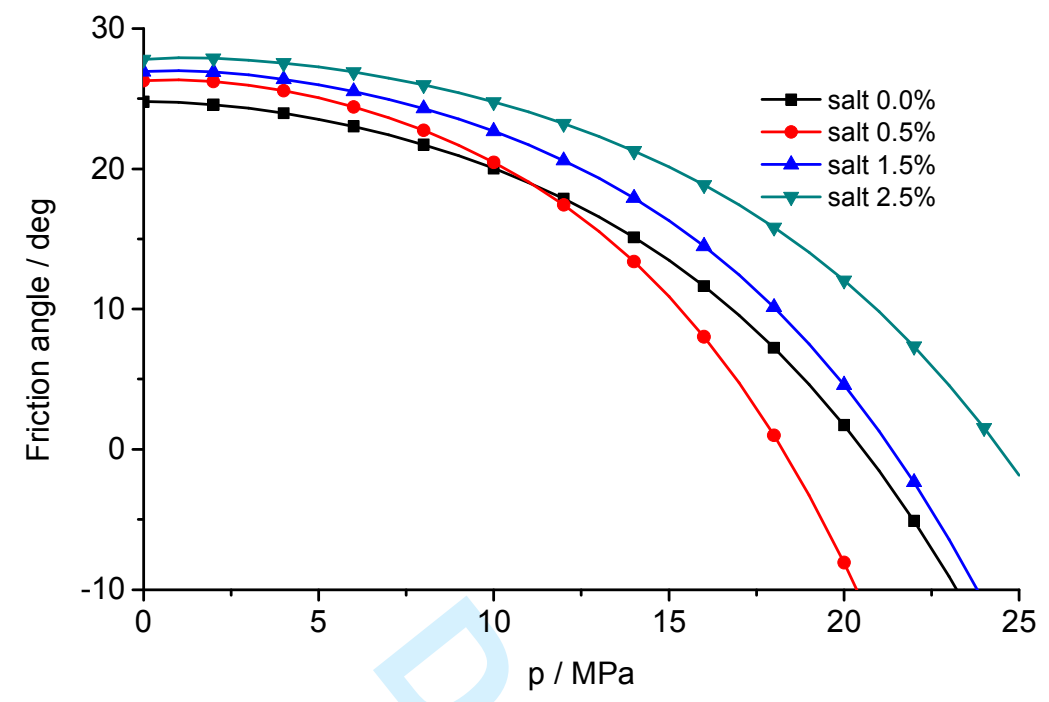

Fig. 5 Relationship between hydrostatic pressure and friction angle for the frozen saline soils with different salt contents. 


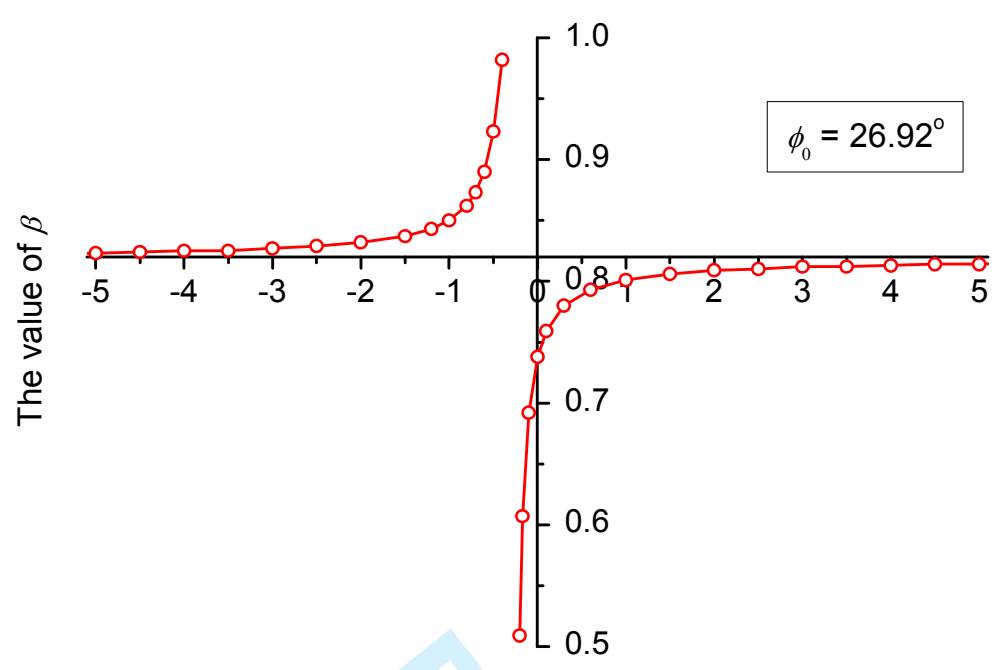

The value of $\alpha$

Fig. 6 Relationship between parameters $\alpha$ and $\beta$ for the frozen saline soil with the salt content of $1.5 \%\left(\phi_{0}=26.92^{\circ}\right)$ 


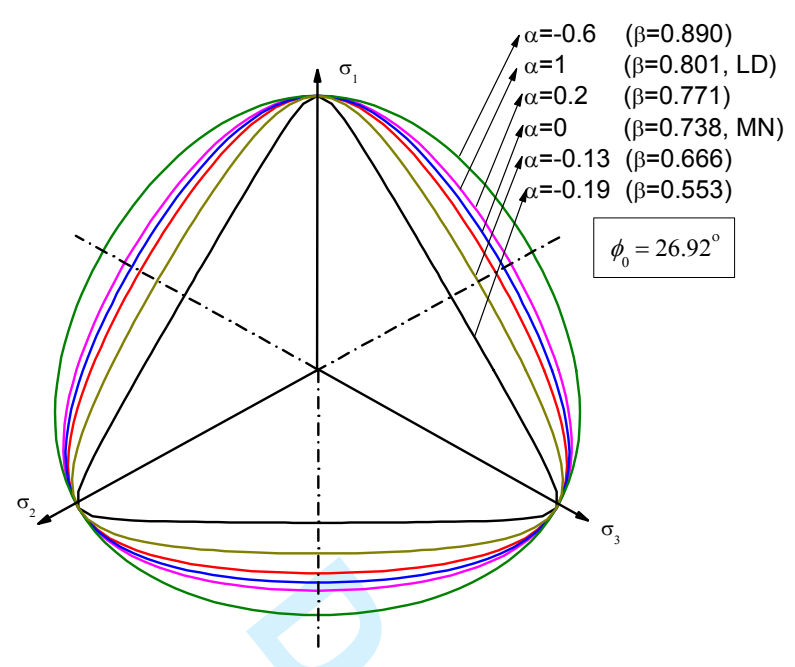

Fig.7 Shape function curves with different values of $\alpha$ in deviatoric plane $\left(\phi_{0}=26.92^{\circ}\right)$ 


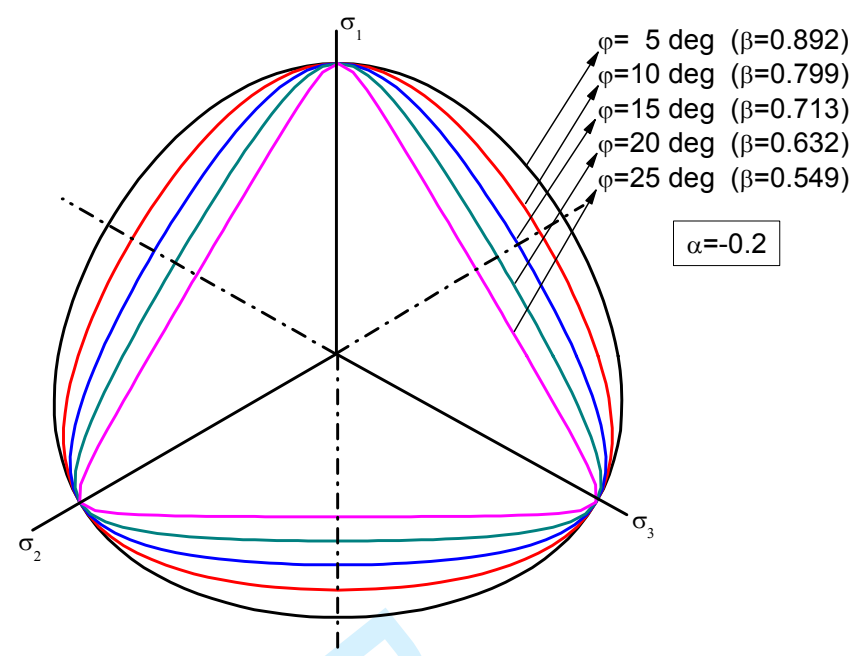

Fig. 8 Shape function curves with different friction angles $\varphi$ and a constant value of $\alpha$ 

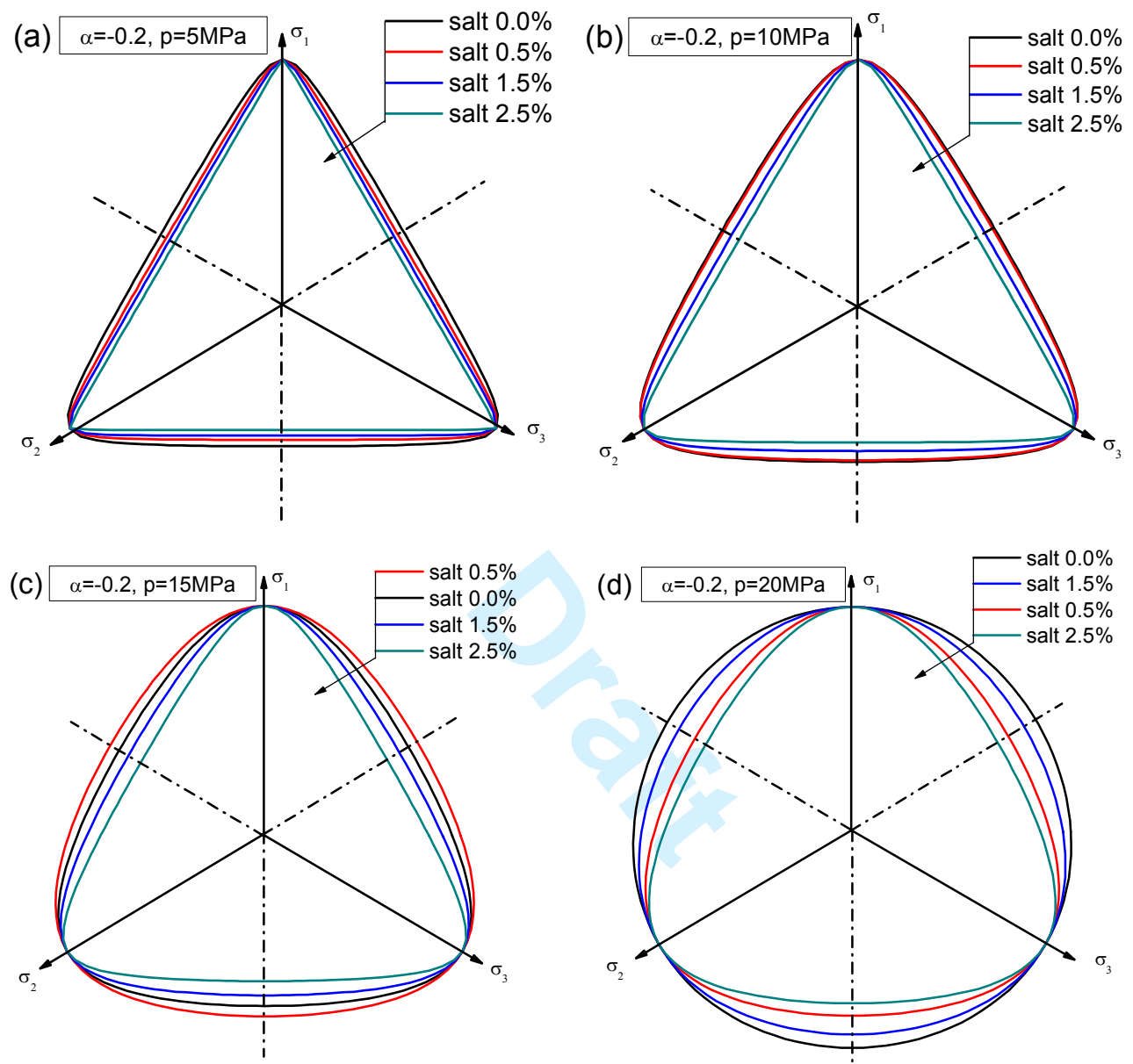

Fig. 9 Shape function curves of the frozen saline soils with different salt contents in deviatoric plane 


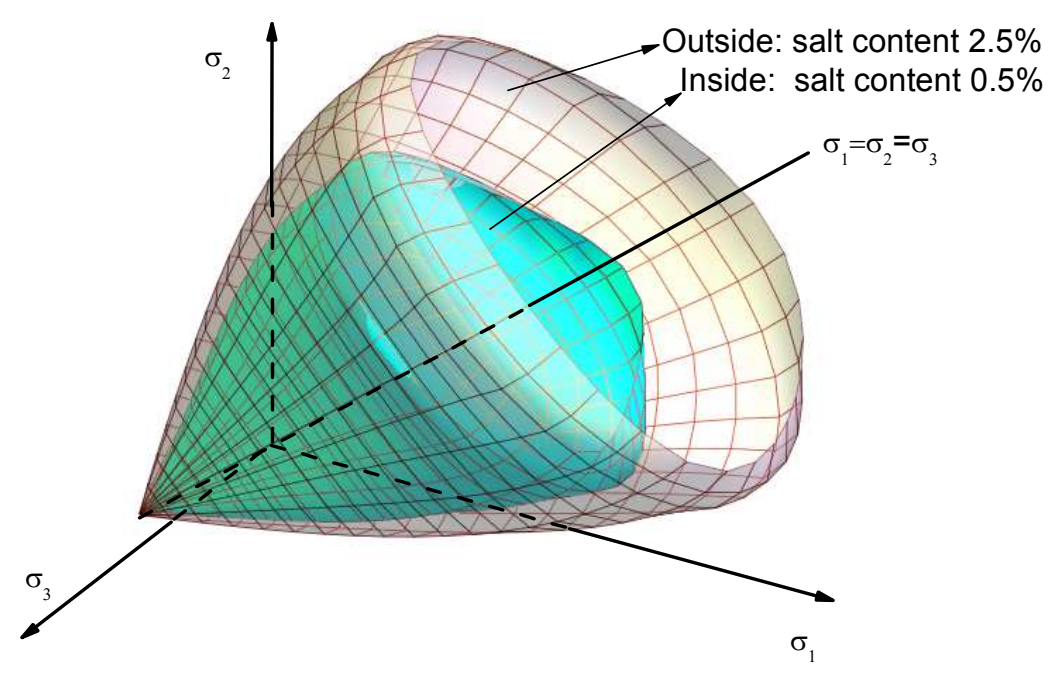

Fig. 10 Yield surfaces of the frozen saline soils with different salt contents in principle stress space 


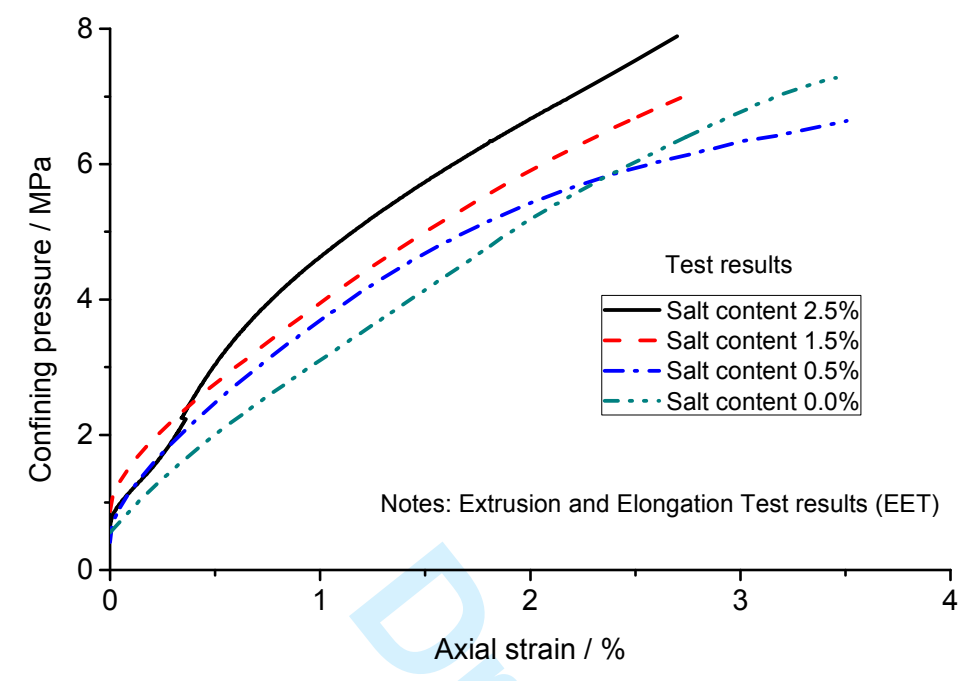

Fig. 11 Relationship between confining pressures and axial strain for the frozen saline soils with different salt contents 


\section{List of Tables}

Table 1 Parameters of critical strength with different salt contents

\begin{tabular}{ccccc}
\hline Salt contents $(\mathrm{S} \%)$ & $0.0 \%$ & $0.5 \%$ & $1.5 \%$ & $2.5 \%$ \\
\hline$M_{0}$ & 1.0934 & 1.2032 & 1.2268 & 1.2777 \\
$B_{l}$ & 18.112 & 15.419 & 17.869 & 19.570 \\
$C_{l}$ & 5.6140 & 4.8022 & 5.5427 & 5.7303 \\
\hline
\end{tabular}

Table 2 Related parameters obtained from the EET tests

\begin{tabular}{|c|c|c|c|c|c|c|c|}
\hline \multirow{2}{*}{$\begin{array}{l}\text { Salt } \\
\text { contents } \\
(\%)\end{array}$} & \multicolumn{2}{|c|}{ Failure stress states (MPa) } & \multirow[b]{2}{*}{$\phi_{0}(\operatorname{deg})$} & \multirow[b]{2}{*}{$p(\mathrm{MPa})$} & \multirow[b]{2}{*}{$\phi(\operatorname{deg})$} & \multirow[b]{2}{*}{$\alpha$} & \multirow[b]{2}{*}{$\beta$} \\
\hline & $\sigma_{1}=\sigma_{2}$ & $\sigma_{3}$ & & & & & \\
\hline 0.0 & 6.032 & 0.50 & 24.77 & 4.188 & 23.87 & -0.204 & 0.552 \\
\hline 0.5 & 5.940 & 0.80 & 26.26 & 4.226 & 25.44 & -0.201 & 0.531 \\
\hline 1.5 & 6.686 & 0.66 & 26.92 & 4.676 & 26.12 & -0.196 & 0.545 \\
\hline 2.5 & 7.531 & 0.30 & 27.78 & 5.121 & 27.21 & -0.170 & 0.601 \\
\hline
\end{tabular}

